\title{
The importance of knowing the home conditions of patients receiving long-term oxygen therapy
}

\author{
This article was published in the following Dove Press journal: \\ International Journal of COPD \\ 4 July 2012 \\ Number of times this article has been viewed
}

\section{Ilda Godoy' \\ Suzana Erico Tanni ${ }^{2}$ \\ Carme Hernández ${ }^{3}$ \\ Irma Godoy ${ }^{2}$}

'Department of Nursing, Botucatu School of Medicine, Universidade Estadual Paulista, Botucatu, São Paulo, Brazil; '2Department of Pulmonology, Botucatu School of Medicine, Universidade Estadual Paulista, São Paulo, Brazil; ${ }^{3}$ Integrated Care Unit, Hospital Clinic, Barcelona, Spain
Correspondence: Ilda Godoy Alameda das Sibipirunas, 23I, Parque das Cascatas, Botucatu, São Paulo, Brazil, CEP: 18607-330

Tel +55 I4 38I5 I466

$\mathrm{Fax}+55 \quad 1438825387$

Email ildadegodoy@gmail.com
Purpose: Long-term oxygen therapy (LTOT) is one of the main treatments for patients with chronic obstructive pulmonary disease. Patients receiving LTOT may have less than optimal home conditions and this may interfere with treatment. The objective of this study was, through home visits, to identify the characteristics of patients receiving LTOT and to develop knowledge regarding the home environments of these patients.

Methods: Ninety-seven patients with a mean age of 69 plus or minus 10.5 years were evaluated. This study was a cross-sectional descriptive analysis. Data were collected during an initial home visit, using a questionnaire standardized for the study. The results were analyzed retrospectively.

Results: Seventy-five percent of the patients had chronic obstructive pulmonary disease, and $11 \%$ were active smokers. The patients' mean pulse oximetry values were $85.9 \%$ plus or minus $4.7 \%$ on room air and $92 \%$ plus or minus $3.9 \%$ on the prescribed flow of oxygen. Most of the patients did not use the treatment as prescribed and most used a humidifier. The extension hose had a mean length of 5 plus or minus $3.9 \mathrm{~m}$ (range, 1.5-16 m). In the year prior to the visit, $26 \%$ of the patients received emergency medical care because of respiratory problems. Few patients reported engaging in leisure activities.

Conclusion: The home visit allowed us to identify problems and interventions that could improve the way LTOT is used. The most common interventions related to smoking cessation, concentrator maintenance and cleaning, use of a humidifier, and adjustments of the length of the connector hose. Therefore, the home visit is a very important tool in providing comprehensive care to patients receiving LTOT, especially those who show lack of adequate progress and those who show uncertainty about the treatment method.

Keywords: LTOT, home visits, chronic obstructive pulmonary disease (COPD), treatment compliance

\section{Introduction}

Long-term oxygen therapy (LTOT) is one of the main treatments for patients with stage IV chronic obstructive pulmonary disease (COPD) and is associated with improved survival ("Evidence A," according to the evidence level scheme employed in previous Global Initiative for Chronic Obstructive Lung Disease reports). ${ }^{1}$ Other benefits of treatment include hemodynamic improvement in hematological parameters, increased exercise capacity, improved quality of life, and improved mental state. ${ }^{1-4}$

The home conditions for use of a complex treatment such as LTOT can be far from ideal..$^{5}$ The recommendations made when prescribing may not be carried out at home, and treatment noncompliance interferes with the effectiveness of LTOT. ${ }^{6}$ A study by Hjalmarsen et $\mathrm{al}^{7}$ showed that patients with hypoxemia who did not undergo 
follow-up supervised by a specialist had worse survival rates than patients who were monitored regularly by specialized staff. In addition, an Italian study that evaluated 1504 patients with severe hypoxemia showed that patient compliance can be improved with multiple educational sessions about the need to use LTOT. ${ }^{8,9}$ Data from the literature show that prescription compliance in patients receiving LTOT is less than ideal, and only $37 \%-65 \%$ of patients use the treatment for more than 15 hours a day. ${ }^{10-12}$

The home visit may be a supplement to the doctor's prescription, as a means to follow up on patients receiving LTOT, especially for those who cannot travel to the hospital or who miss scheduled appointments. Home visits are usually well accepted by patients who require stricter control. ${ }^{13}$ However, the essential components, appropriate professionals, frequency of visits, and minimum duration required to achieve the desired benefits of home visits have not yet been established. ${ }^{14}$

The home visits generally include interviews, systematic observation, and guided and participatory intervention. The home visit is a way for the health care professional to access the home and living environment of patients; these professionals seek to educate, prevent, restore, and maintain the health of LTOT recipients in the context of their own homes. ${ }^{15}$ In this regard, the goal of this study was to identify the characteristics of patients receiving LTOT who were residing in the municipality of Botucatu, Brazil, and to develop knowledge regarding the home environments of these patients. These patients received care at the LTOT clinic at the Clinical Hospital of the Botucatu School of Medicine, Universidade Estadual Paulista. Through this, the authors hope to propose intervention measures to improve quality of care and treatment outcomes.

\section{Methods}

Retrospective data were collected during the first home visit to LTOT recipients who were outpatients of the Clinical Hospital of the Botucatu School of Medicine between January 2006 and December 2009. Patients with chronic respiratory failure of any etiology who met the criteria for LTOT recommended for patients with COPD and chronic hypoxemia were included in the study. The criteria for LTOT according to the Brazilian guidelines for COPD patients are as follows: a partial pressure of oxygen in the blood of $<55 \mathrm{mmHg}$ or a saturation level of oxygen in hemoglobin of $<88 \%$; alternatively, a partial pressure of oxygen in the blood between 56 and $59 \mathrm{mmHg}$ or a saturation level of oxygen in hemoglobin of $89 \%$ with evidence of pulmonary hypertension, peripheral edema, suggestive cardiac failure, or polycythemia (hematocrit, $55 \%) .{ }^{16}$ All 97 patients treated during the period stated were included in the study. The home visit occurred after 6 months of the prescription of LTOT. At the point of the home visit, patients had already visited the outpatient clinic twice. During these visits, patients had been strongly recommended to use the oxygen in compliance with the prescription and they had received all the orientations about LTOT use at home. In addition to this, the indication for LTOT was, according to the guidelines, no longer temporary. ${ }^{16}$ The authors assessed demographic variables, active or passive exposure to smoking, pulse oximetry while breathing the prescribed oxygen flow and after 20 minutes of breathing room air, the maintenance and proper use of the concentrator, compliance with the oxygen prescription (hours/day and flow), medication use, visits to the emergency room, sleep conditions, and leisure activities performed. The guidance provided to these patients was also noted. Data were collected through a standardized questionnaire. Pulse oximetry was performed using portable equipment (Onyx 9500 pulse oximeter; Nonin Medical Inc, Minneapolis, MN).

The Ethics Committee of the Botucatu School of Medicine, Universidade Estadual Paulista approved the study; patients were instructed about the objectives of the study and all patients signed an informed consent document.

\section{Results}

Ninety-seven patients receiving LTOT were evaluated. The patients had a mean age of 69 plus or minus 10.5 years (range, 43-94 years), and 50\% of patients were female. None of the patients were economically active: the majority $(89 \%)$ supported themselves from retirement income, while $11 \%$ had no formal income. The primary diagnosis was COPD in $75 \%$ of patients (Table 1 ).

Twenty-five patients experienced active or passive exposure to cigarette smoke. Eleven patients (11\%) were active smokers, and of these, five smoked indoors. In addition, 14 patients had family members who smoked, and in three of these cases the patients reported that their family members smoked inside the house.

Table I Primary diagnosis of long-term oxygen therapy recipients $(n=97)$

\begin{tabular}{ll}
\hline Diagnosis & Recipients (\%) \\
\hline Chronic obstructive pulmonary disease & 75 \\
Pulmonary arterial hypertension & 7 \\
Obstructive sleep apnea syndrome & 5 \\
Interstitial lung disease & 5 \\
Other illnesses & 8 \\
\hline
\end{tabular}


Table 2 Characteristics of oxygen $\left(\mathrm{O}_{2}\right)$ prescription and equipment $(n=97)$

\begin{tabular}{ll}
\hline Characteristic & Result \\
\hline Proper use of $\mathrm{O}_{2}$ (flow and time) (yes/no [\%]) & $37 / 63$ \\
Use of water in humidifier (yes/no [\%]) & $97 / 3$ \\
Backup tank (yes/no [\%]) & $100 / 0$ \\
Mean length of connector hose (m) & $5 \pm 3.9$ \\
\hline
\end{tabular}

When breathing room air, the patients' mean pulse oximetry value was $85.9 \%$ plus or minus $4.7 \%$ (range, $82 \%-95 \%$ ). They referred to use oxygen supplementation for 18.5 plus or minus 4.9 hours/day. The mean oximetry value on the prescribed oxygen flow rate was $92 \%$ plus or minus $3.9 \%$ (range, $82 \%-97 \%$ ).

The characteristics of oxygen prescription and oxygen equipment use are presented in Table 2. It was observed that most patients did not use the treatment as prescribed and most used a humidifier. All patients had an oxygen tank for use in the event of concentrator failure. The extension hose had a mean length of 5 plus or minus $3.9 \mathrm{~m}$ (range, 1.5-16 m).

Most patients regularly used specific pharmacological treatment for respiratory problems (64\%) or comorbid conditions $(85 \%)$. In the year prior to the home visit, $38 \%$ of patients visited the emergency room (26\% for respiratory problems; twelve ( $46 \%$ ) of these patients were hospitalized). Thirty-one (32\%) patients reported not sleeping well - 90\% of these patients attributed their insomnia to the noise from the concentrator and $10 \%$ attributed it to dyspnea.

Table 3 shows the guidance provided to LTOT recipients during the home visit. Smokers were counseled about the need to stop smoking and the available treatments for doing so; passive smokers were instructed on how to reduce exposure. Most recommendations focused on measures to increase compliance with the LTOT.

A few patients $(28 \%)$ reported performing physical and leisure activities, including attending church, spending time in the town square, rehabilitation, walking, fishing, crafts, housecleaning, and caring for animals. LTOT recipients expressed a desire to perform simple daily life activities related to independence and autonomy.

Table 3 Guidance provided to long-term home oxygen $\left(\mathrm{O}_{2}\right)$ therapy recipients $(n=97)$ during the home visit

\begin{tabular}{ll}
\hline Guidance & Recipients [n (\%)] \\
\hline Apparatus maintenance and cleaning & $60(62)$ \\
Proper use of $\mathrm{O}_{2}$ (hours/day and flow) & $61(63)$ \\
Smoking cessation & $8(8,3)$ \\
Adjustment or replacement of connector hose & $5(5.1)$ \\
No guidance & $2(2.1)$ \\
\hline
\end{tabular}

\section{Discussion}

LTOT is an effective treatment, but it may be less effective than expected for several reasons. One of the most important reasons is compliance with the prescription and guidance on the proper use of equipment. Seventy-five percent of the patients in the sample evaluated in this study had a diagnosis of COPD; this number is comparable with that reported in similar studies, where the proportion of patients with this diagnosis has ranged from $67.8 \%$ to $81.7 \% .{ }^{17-20}$ The major findings of the present study showed that most patients did not use LTOT according to the prescription. One-quarter of patients were exposed to smoking, and one-quarter required emergency medical care for respiratory problems. Most patients did not perform occupational or leisure activities, and, as stated earlier, 11\% had no formal income.

In general, treatment regimens involving a change in the patient's lifestyle have a higher degree of noncompliance, requiring the active participation of the physician and the health care team for treatment to be effective. ${ }^{21}$ The effectiveness of LTOT depends on the correct indication and the patient's compliance with the prescription. ${ }^{22}$ In the present study, many patients used the treatment in ways contrary to the prescription. Compliance with the LTOT prescription is difficult to assess because it involves factors dependent on the individual, the disease itself, and the type of treatment and the equipment required. In a similar study carried out in Spain, compliance ranged from $10 \%$ to $51 \%{ }^{23,24}$ In the present study, prescription compliance regarding the number of hours spent per day receiving oxygen and the flow was 37\%. Lack of treatment compliance can result in increased morbidity, greater impairment of quality of life, increased health costs, more frequent hospitalizations, and possibly a higher mortality. Compliance can be affected by a patient's perception of his or her illness, treatment, or medication used and the patient's perception of the quality of communication between health professional and patient, preparation from his or her caregiver, and the social environment. Studies indicate that failure to consider individual circumstances while prescribing is associated with noncompliance. ${ }^{25}$

In addition to low levels of compliance, another factor that may influence the effectiveness of LTOT is exposure to smoking. COPD is predominantly a disease caused by smoking, and it has no cure. However, smoking cessation can slow disease progression and is considered the main intervention in disease management. ${ }^{26,27}$ Smoking should be thought of as a vital sign. All smokers with COPD should be encouraged to stop smoking, and help in stopping smoking should be offered to them at every opportunity. ${ }^{28}$ There is an obvious concern 
for safety, along with uncertainty about the likely benefit of LTOT in patients who continue to smoke. Population studies that examine the prevalence and characteristics of smoking among individuals diagnosed with COPD receiving LTOT have shown that the prevalence of smoking in this group is high and that these patients have a higher degree of physical dependence on nicotine than smokers without COPD. ${ }^{26-29}$ A smoking rate of $11 \%$ was noted in the present study, while $26 \%$ of patients were exposed to cigarette smoke; this is the same smoking rate as that found in a previous study of COPD patients conducted in Madrid (11\%). ${ }^{26}$ More recently, the results of another study of COPD patients in Madrid showed a lower prevalence of smoking $(5.7 \%) .{ }^{29}$ The decrease in smoking prevalence may not indicate the decline of smoking in these patients but, rather, the restrictions imposed by the prescribed therapy among this group of patients with COPD.

There is no scientific evidence indicating the need for humidification in systems that employ nasal catheters and at flows below $5 \mathrm{~L} / \mathrm{min}$, except in cases of transtracheal use or use through tracheostomies. ${ }^{30}$ Ninety-seven percent of patients in the present study used a humidifier although, as there is no evidence for the effectiveness of humidifiers, this was not recommended by the health care service. However, companies that install LTOT equipment in the patient's home often recommend the use of a humidifier. In the present study, the connector hoses had a mean length of 5 plus or minus $3.9 \mathrm{~m}$. The guidelines for the use of LTOT indicate that the connector hose should have a maximum length of $20 \mathrm{~m}$ (preferably a single-piece hose with no connectors). One must be careful not to allow air to escape through the fittings on the pressure gauge and nasal masks, or through any connectors in the hose, if connections are necessary. The connector should be cleaned weekly with water and soap. ${ }^{16,31}$ In some cases in the present study the hose length was shorter than the length necessary to allow patients to perform activities of daily living. Where this was the case, recommendations to adjust it were made during the home visit.

Despite recent progress in understanding the mechanisms and treatment of COPD, flare-ups are important events. Hospitalization for flare-ups is a major problem in the management of COPD because of the negative impact on quality of life, on prognosis, and on the cost of the disease..$^{32,33}$ In the present study, $26 \%$ of patients were treated in emergency departments for respiratory problems, and twelve (46\%) of these patients were hospitalized. Since treatment compliance is related to COPD morbidity, knowledge of patients' home conditions and measures to improve treatment compliance and efficacy can be tools for helping to reduce the number of patient hospitalizations.
There is little information available about the daily activities of patients with COPD. Previous studies have shown that patients with stable COPD are inactive in daily life and spend most of the day sitting or lying down. ${ }^{34,35}$ Patients with COPD experience a spontaneous reduction in physical activity levels compared with healthy persons. ${ }^{36,37}$ Furthermore, those who receive LTOT have an even lower level of physical activity than patients who do not receive LTOT, even when they have a similar degree of COPD. ${ }^{37}$ Results of qualitative studies have shown that patients receiving LTOT need help coping with both the various psychological and physiological difficulties encountered and the social isolation. These patients have insufficient resources for daily life and are homebound, experiencing problems with mobility and dependency. Although dependence on another family member is an important factor, the issue that stands out is social isolation. ${ }^{38}$ The results of the present study are consistent with these findings: only $28 \%$ of patients in the present study performed any type of leisure or physical activity.

\section{Conclusion}

The results of this study show that home visits helped to identify problems and to implement interventions that may have improved the way LTOT was used. Interventions helped with recommendations for the number of hours and the flow prescribed, smoking cessation, concentrator maintenance and cleaning, use of a humidifier, and length of the connector hose. Therefore, knowledge of the home conditions of patients receiving LTOT constitutes a key tool in providing comprehensive care, especially for those patients who do not show adequate progress and for those who are unsure about the expected results and/or how to use the treatment.

\section{Disclosure}

The authors report no conflicts of interest in this work.

\section{References}

1. Global Initiative for Chronic Obstructive Lung Disease (GOLD). Global strategy for the diagnosis, management, and prevention of COPD. GOLD; 2010. Available from: http://www.goldcopd.org/. Accessed January 10, 2012.

2. Morrison D, Skwarski KM, MacNee W. The adequacy of oxygenation in patients with hypoxic chronic obstructive disease treated with long-term domiciliary oxygen. Respir Med. 1997;91(5):287-291.

3. Haidl P, Clement C, Wiese C, Dellweg D, Köhler D. Long-term oxygen therapy stops the natural decline of endurance in COPD patients with reversible hypercapnia. Respiration. 2004;71(4):342-347.

4. Tanni SE, Vale SA, Lopes PS, Guiotoko MM, Godoy I, Godoy I. Influence of the oxygen delivery system on the quality of life of patients with chronic hypoxemia. J Bras Pneumol. 2007;33(2):161-167. English, Portuguese.

5. Escarrabill J. Atención domiciliaria en la enfermedad pulmonar obstructiva crónica (EPOC). JANO. 2003;65(1500):1986-1988. 
6. Granados A, Escarrabill J, Borràs JM, Rodríguez-Roisín R. The importance of process variables analysis in the assessment of long-term oxygen therapy by concentrator. Respir Med. 1997;91(2):89-93.

7. Hjalmarsen A, Melbye H, Wilsgaard T, Holmboe JH, Opdahl R, Viitanen M. Prognosis for chronic obstructive pulmonary disease patients who receive long-term oxygen therapy. Int J Tuberc Lung Dis. 1999;3(12):1120-1126.

8. Neri M, Melani AS, Miorelli AM, et al. Long-term oxygen therapy in chronic respiratory failure: Multicenter Italian Study on Oxygen Therapy Adherence (MISOTA). Respir Med. 2006;100(5):795-806.

9. George J, Kong DC, Stewart K. Adherence to disease management programs in patients with COPD. Int J Chron Obstruct Pulmon Dis. 2007;2(3):253-262.

10. Eaton T, Lewis C, Young P, Kennedy Y, Garrett JE, Kolbe J. Long-term oxygen therapy improves health-related quality of life. Respir Med. 2004;98(4):285-293.

11. Janssens JP, Rochat T, Frey JG, Dousse N, Pichard C, Tschopp JM. Health-related quality of life in patients under long-term oxygen therapy: a home-based descriptive study. Respir Med. 1997;91(10):592-602.

12. Górecka D, Gorzelak K, Sliwiński P, Tobiasz M, Zieliński J. Effect of long-term oxygen therapy on survival in patients with chronic obstructive pulmonary disease with moderate hypoxaemia. Thorax. 1997;52(8):674-679.

13. Munilla E, Carrizo S, Hernández A, Vela J, Marín JM. Oxigenoterapia continua domiciliaria em Zaragoza: estudo transversal a domicilio. Continuous domiciliary oxygen therapy in Zaragoza: a cross-sectional home study. Arch Bronchoneumol. 1996;32(2):59-63. Spanish.

14. Farrero E, Prats E, Maderal M, Giró E, Casolivé V, Escarrabill J. Utilidad de la visita a domicilio en el control y valorición del uso apropiado de la oxigenoterapia continua domiciliaria. Usefulness of home visits in the control and evaluation of the appropriate use of home continuous oxygen therapy. Arch Bronchoneumol. 1998;34(8):374-378. Spanish.

15. Egry EY, da Fonseca RM. A familia, a visita domiciliaria e a enfermagem: revisitando o processo de trabalho da enfermagem em saúde coletiva. Family, home visiting and nursing: reviewing the work process of nursing in collective health. Rev ESC Enferm USP. 2000;34(3):233-239. Portuguese.

16. Brazilian Society of Pulmonology and Phthisiology. Oxigenoterapia domiciliar prolongada. J Bras Pneumol. 2000;26:341-350.

17. Manresa J, Caballol R, Sena F. El control de la oxigenoterapia domiciliaria en un hospital comarcal. Monitoring domiciliary oxygen therapy from a district hospital. Arch Bronconeumol. 2001;37(7):237-240. Spanish.

18. Ström K. Survival of patients with chronic obstructive pulmonary disease receiving long-term domiciliary oxygen therapy. Am Rev Respir Dis. 1993;147(3):585-591.

19. Dela Coleta K, Silveira LV, Lima DF, Rampinelli EA, Godoy I, Godoy I. Predictors of first-year survival in patients with advanced COPD treated using long-term oxygen therapy. Respir Med. 2008;102(4):512-518.

20. Lima DF, Dela Coleta K, Tanni SE, Silveira LV, Godoy I, Godoy I. Pontentially modiafiable predictors of mortality in patients treated with long-term oxygen therapy. Respir Med. 2011;105(3):470-476

21. Díaz Lobato S, Pino García JM, Villasante C. Facotres que influyen en el coste económico de la oxigenoterapia domiciliaria. Factors influencing economic cost of home oxygen therapy. Med Clin (Barc). 1998;110(8):303-306. Spanish.

International Journal of COPD

\section{Publish your work in this journal}

The International Journal of COPD is an international, peer-reviewed journal of therapeutics and pharmacology focusing on concise rapid reporting of clinical studies and reviews in COPD. Special focus is given to the pathophysiological processes underlying the disease, intervention programs, patient focused education, and self management protocols.
22. Parra O, Palau M, Barrueco M, et al. Efectos de la visita domiciliaria (VD) en el cumplimiento de la prescripción de la oxigenoterapia domiciliaria (OD). Estudio multicéntrico. Arch Bronconeumol. 2001;37(4): 206-211. Spanish.

23. Escarrabill J, Estopà R, Huguet M, Manresa F. Domiciliary oxygen therapy. Lancet. 1985;2(8458):779.

24. Solé J, Monasterio C, Escarrabill J. Cumplimiento de la prescripción en la oxigenoterapia domiciliaria. Arch Bronconeumol. 1992;28:253-254. Spanish.

25. May C, Montori VM, Mair FS. We need minimally disruptive medicine BMJ. 2009;339:b2803.

26. Rodriguez-Roisin R. Toward a consensus definition for COPD exacerbations. Chest. 2000;117(5 Suppl 2):S398-S401.

27. Jiménez-Ruiz CA, Masa F, Miravitlles M, et al. Smoking characteristics: differences in attitudes and dependence between healtly smokers and smokers with COPD. Chest. 2001;119(5):1365-1370.

28. Shahab L, Jarvis MJ, Britton M, West R. Prevalence, diagnosis and relation to tobacco dependence of chronic obstructive pulmonary disease in a nationally representative population sample. Thorax. 2006;61(12):1043-1047.

29. Cienfuegos Austín I, Martín Escribano P, López Encuentra A, Salama Benoniel R. High prevalence of long-term domiciliary oxygen therapy with a low percentage of inappropriate prescription in the Madrid health care area: evaluation of the correct use. Arch Bronconeumol. 2000;36(3):139-145. Spanish.

30. Fulmer JD, Snider GL. ACCP-NHLBI national conference on oxygen therapy. Chest. 1984;86(2):234-247.

31. Sánchez Agudo L, Cornudella R, Estopá Miró R, Molinos Martín L, Servera Pieras E. Normativa SEPAR para la indicación y empleo de la oxigenoterapia continua domiciliaria (OCD). Guidelines for indications and use of domiciliary continuous oxygen (DCO) therapy: SEPAR guidelines. Arch Bronconeumol. 1998;34(2):87-94. Spanish.

32. Murray CJ, Lopez AD. Mortality by cause for eight regions of the world: Global Burden of Disease Study. Lancet. 1997;349(9061) 1269-1276.

33. Jiménez-Ruiz CA, de Lucas Ramos P, Díaz Lobato S, et al. Study of prevalence and attitudes on smoking in patients on continuous home oxygen therapy: Toma Study. Arch Bronconeumol. 2010;46(11):580-586. Spanish.

34. Sandland CJ, Morgan MD, Singh SJ. Patterns of domestic activity and ambulatory oxygen usage in COPD. Chest. 2008;134(4):753-760.

35. Singh SJ, Morgan MD. Activity monitors can detect brisk walking in patients with chronic obstructive pulmonary disease. J Cardiopulm Rehabil. 2001;21(3):143-148.

36. Sandland CJ, Singh SJ, Curcio A, Jones PM, Morgan MD. A profile of daily activity in chronic obstructive pulmonary disease. J Cardiopulm Rehabil. 2005;25(3):181-183.

37. Pitta F, Troosters T, Spruit MA, Probst VS, Decramer M, Gosselink R. Characteristics of physical activities in daily life in chronic obstructive pulmonary disease. Am J Respir Crit Care Med. 2005;171(9):972-977.

38. Ring L, Danielson E. Patients' experiences of long-term oxygen therapy. J Adv Nurs. 1997;26(2):337-344.
This journal is indexed on PubMed Central, MedLine and CAS. The manuscript management system is completely online and includes a very quick and fair peer-review system, which is all easy to use. Visit http://www.dovepress.com/testimonials.php to read real quotes from published authors. 